\title{
Sprawl Growth of Yasuj City, a Barrier to Achieve Sustainable Development
}

\author{
Gholam Ali Khammar \\ Assistant Professor, Geography and Urban Planning, University of Zabol, Iran \\ Tel: 98-091-5342-0818Ｅ-mail: Ah.khammar@gmail.com
}

\begin{abstract}
Akbar kiani
Associate Professor, Geography and Urban Planning, University of Zabol, Iran

Tel: 98-091-2246-3826 E-mail: kianiakbar@gmail.com
\end{abstract}

\begin{abstract}
Ali Ashkabos (Corresponding author)
Ms.c student, Geography and Urban Planning, University of Zabol, Iran

Tel: 98-093-661-444-982Ｅ-mail: aliashkbos@yahoo.com
\end{abstract}

\begin{abstract}
Sajjad Ghasemi Kafrudi
Ms.c student, Geography and Urban Planning, University of Kharazmi Tehran, Iran

Tel: 98-091-3870-2420Ｅ-mail: sajadghasemi68@yahoo.com
\end{abstract}

Received: February 15, 2014 Accepted: March 11, 2014

doi:10.5296/emsd.v3i1.5124 URL: http://dx.doi.org/10.5296/emsd.v3i1.5124

\begin{abstract}
In times past, the Iranian cities were generally built in the areas where there were wide agricultural hinterland and the importance of cities depended greatly upon this factor. But, gradually by developing technology and using technical equipment, the role of this factor diminished and led to the degradation of these lands around these cities. The present paper has been presented with the purpose of assessing and analyzing the innermost development indices to avoid the irregular growth of the city and destroying agricultural lands in order to achieve sustainable development with regard to the social-economic indices, the exploitation of urban lands, the degradation trend of agricultural lands and gardens, and the ecological
\end{abstract}


indices in the regions of Yasuj city. The research type is an applied-developmental research and the methodology is analytical-descriptive. The Geographic Information System (GIS) has been utilized to analyze the indices. The findings show that with regard to the innermost growth indices to avoid the irregular growth of city, Yasuj city, except for little cases, has not benefited from a proper performance for urban sustainable development.

Keywords: Irregular growth, sustainable development, agricultural lands, Yasuj, GIS

\section{Introduction}

City is the main center of human civilization and the mental and technological manifestation of human being. The study of levels and the growth of urbanization reflect the fact that urban population growth is increasing rapidly (Seifoldini, 1997). In the past, the process of changing in the growth of cities was done slowly, and equipment, instruments variation, building materials, and technology as well as tastes were limited and the customary and cultural system acted well which led to the cities with a harmonious and sustainable shape and appearance (Salehi, 2006). Nowadays, there is a common sense among all people that most of urban regions are inappropriate and undesirable. That is, they are uncomfortable, ugly, confusing and anonymous places (Lynch, 1997). The rapid growth of population and their concentration into cities all over the world affect the life perspective of most human being. The crises of this rapid growth are poverty, environmental degradation, lack of urban services, the collapse of the available infrastructure, and the lack of accessing to land and shelter. The urban planning of the 20th century ended while not only has it not been assessed a positive planning, but also it has not been presented as a beautiful appearance against the urban environment, and pointed to the biological and social structures by technical culture, which consequently led to the instability and imbalance in the natural, social, economic, and physical infrastructure (Ziari, 2001).

The theory of sustainable development and urban sustainable development require changing in political, social, physical, economical, and ecological infrastructures which should be provided by management and urban development planning on the basis of principles framework of sustainable development. Nowadays, almost all urban areas undergone the endogenous and exogenous factors (urban and extra-urban) including population movements, economic dynamism, national policies, programs, actions, and decisions of management collection are growing.

The case study in this research is Yasuj city, in Kohgiluyeh and Boyer-Ahmad Province in Iran, with an inharmonious development. Due to the location of the city in mountainous conditions and agricultural lands, this development has generally been with degradation of agricultural lands. Regarding the rapid changes of population and the physical development of the city, the need for planned development is felt more than ever. With regard to the effective factors in this development, the physical development orientation should be done in a way that, with the urban desirable development, cause the least damage to the agricultural lands and gardens and could achieve urban sustainable development by maintaining a healthy environment, a development in which the economic, cultural, social, and physical purposes should be together in pairs. 


\section{Background and Significance of the Study}

Urbanization as the second revolution in human culture after agriculture has caused variation in human interaction with each other and by increasing the urban population, the exploitation of the environment is intensified (Parhizgar, 1997). The rapid growth of Urbanization and the emergence of metropolises have led to the different consequences and have accompanied with the diverse urban damages. Physical abnormalities, abnormalities of the installation, economic damages, ecological damages, lack of services, and finally social damages in urban domains are considered as the consequences of rapid urbanization (Aliakbari, 2002).

With regard to the mentioned issues about development, the sustainable development of every city must be parallel with the indices of the sustainable development of that city. The domination of human society and the increment of the urban development in society have caused the urban system pay a special attention to achieve sustainability (Gharakhloo \& Hosseini, 2006).

Ebrahimzadeh and Rafiee (2010) in their study, "An Analysis on the Physical-Spatial Pattern of Marvdasht Township by Entropy Models...", examined the growth of Marvdasht township. Based on this study, the growth of the township has been in a concentrated manner up to the year 1996, and after that it has been in a sprawl way. Regarding the increase in the entropy value gap due to the spiral growth, the centralized-sectorial pattern was determined and suggested as a desirable pattern for the future development of it.

"Sustainable cities in developing countries" (2004) written by Cedric Pag, translated by Naser Moharamnejad, Center for Architectural and Urban Studies and Researches, Tehran, Iran. The topic of this book is the urban sustainable environment in developing countries. Its chapters and concepts describe the social, economic, and ecological concepts and discuss the interrelationships and interactions as well as the characteristics and potentials of these cities.

The present study attempted to examine the innermost growth indices (social-economic indices, urban land exploitation, the process of the degradation of agricultural lands and gardens, and ecological indices) to prevent from the irregular growth in Yasuj city and the degradation of desirable lands around it.

\section{Methodology}

Yasuj city is located in one of the beautiful provinces of Iran, namely, Kohgiluyeh and BoyerAhmad province which enjoys diverse attractions and natural landscapes and also culturalhistorical valuable attractions. The verdurous and beautiful forests of oak, fountains replete with water, numerous permanent and seasonal lakes, beautiful mountains, jungle parks, weather duality and temperature difference with the distance of only 30 kilometre, the nice scent of wild herbs and local of the province, vast plains with beautiful perspectives, having the condition of a four-season climate, roaring rivers and numerous waterfalls, the existence of the shrine of hundreds of Imamzadeh, as well as hundreds of ancient monuments from different historical periods can be considered as one part of the tourist attractions of this unknown boundary.

Yasuj city, which is now considered as the capital of the province, was established with the 
current form and with the current location in 1342 Hijri. The construction of Yasuj was started with the permission of the government in the region of Sar-rood. But before the establishment of Yasuj city, Tel-Khosro city was considered as the urban gathering of the cold region of Sar-rood. Tel-Khosro city was located with a very little distance to the current situation of Yasuj and in the south of it. In the meantime, the city along with the historical part of "Bazrang" and similar to other cities of the province (Dehdasht, Sisakht, and Dogonbadan) have a long historical period. The people of this region during the historical periods were known as Luri race from the wide race of Aryan and they have been paid attention to in the historical works and their social and political destiny have also been indicated. However, regardless of the various opinions stated about the political status and the location and cultural situation of Lurs, it can be said that the whole written works remained from Lurs have reminded Lurs as an Iranian pure and unified race who have settled in the southern Zagros mountains. (http://denaboy.pib.ir).

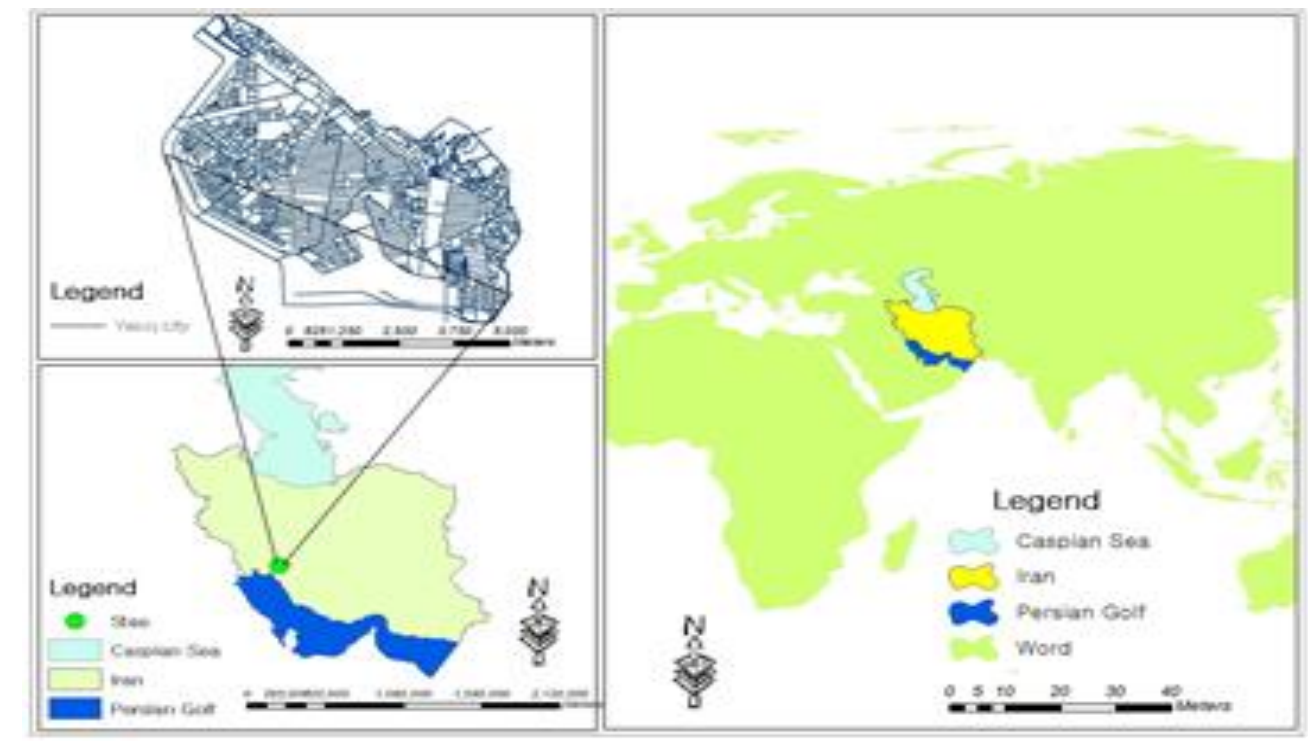

Figure 1. The geographical setting of Yasuj city (authors, 2013)

The choice of an appropriate research methodology for stating the problem under study is very crucial because the choice of an appropriate methodology will help the researcher achieve his/her goals and get him/her rid of confusion, wasting time, and costing. Therefore, regarding the topic and the purposes of the study, the choice of a methodology which can illuminate the genesis system and the evolution of the phenomenon and which will be helpful in its analysis and inference categorization is necessary.

\subsection{Assessment with Geographical Information System (GIS)}

Geographical information system technically provides a powerful tool for assessing geographical environment in support of lands planning. The main feature of this system is the ability to produce new information by means of completing the subscription of a diverse data set available in an adaptable judiciary system (Dia, 2001). GIS system is a very powerful software in the field of storage, analysis, processing, recycling, and displaying the data in the form of map. The use of this software has increased day by day and different sciences use this 
system based on their requirements (Taghipour, 2009), because in GIS the access, conversion, and manipulation of the data are performed informally. This system can be called the laboratory of environmental processes or a means for analyzing the consequences of a determined process or for predicting the results of the planners' decisions (Boro, 1997). Therefore, the methodology of the current study is more descriptive-analytic. The analysis of this problem and the innermost development indices have been conducted with regard to the urban irregular growth for planning and by exploitation of field and library studies. For analyzing each of the research indices and producing maps from GIS and for displaying the situation of suburb limits, due to the lack of GIS map of suburb, the Google Earth and its digitization have been utilized.

\section{Research Theoretical Framework}

\subsection{The Concept of Development and Sustainable Development}

The concept of development has been with mankind from his first existence on earth and has evolved with his material and spiritual improvements. In the course of human contemplation about growth and development and its ecological effects, there are extensive concepts and comprehensive literature the newest of which is the concept of sustainable development. These concepts in geography like any other discipline which is relevant to human and his surroundings have many theoretical and philosophical roots.

The development of idea is a practice which emerged from the beginning of the $19^{\text {th }}$ century. This concept is different from the idea of improvement. Following the dissatisfaction with improvement in the era of western contemplations of the merchants, idealistic and critical positivists, the accompaniment of development theory with the initial capitalism according to the guardianship reasoning (act instead of another), a strong power was created in forming the development theory and guardianship is an intention expressed with an agency source for developing other capacities (Cowen et al, 1996).

The sustainable development means moving on the human-environment axle and pays attention to the development of economic equipment with regard to the environmental considerations and social justice. The sustainable development, after the made problems, was developed from merely economic development after the World War where irregular development had caused classical differences and numerous ecological difficulties and the process of development had paid attention to the environmental and social dimensions less than economic ones. This concept is rooted in an ecological principle. Based on this principle, if in every environment, as much as the natural capacity of producing the environment, the exploitation was performed, the investment principle (ecological resources) would remain sustainably and our use of the environment as much as that production capacity would always be sustainable. Because the use rate of human in that determined environment, which is appropriate to the environment capacities, is as much as the whole production, thus, it has the maximum efficiency (Makhdoom, 2000).

In sustainable development, human beings are the focus of attention and humans adapted to the environment deserve a life associated with safe and healthy. In this trend, the principle of 
balance between the economic, social, and ecological desires of each generation with respect to the share of the future generations from the limited resources of the land is the axle of urban policies and the arrangement of settlements (Amkchi, 2005). Therefore, the concept of sustainable development is a broad meaning which covers all aspects of humans' life in which policies in the field of economic, commercial, technological, natural, educational, healthy, and industrial resources are planned and designed in a way that the social-economic and ecological development were continued (Movahhed, 2001).

\subsection{Innermost Development or Endogenous Development}

Since inner development of city or innermost development, contrary to the other urban development policies, takes place in the context of extant city and with the presence of inhabitants, citizens, and neighbourhood units, it is a complicated, multi-faceted, crosssectoral, and even meta-sectoral issue which not only is a physical and urbanization work but also has strong social, cultural, economic, and ecological dimensions. In inner development of cities, instead of sprawl expansion and degradation of lands around, the city expands vertically. The old, decay, and inefficient contexts of cities are reclaimed and reconstructed. The urban arid and abandoned lands are used. The plans which are inappropriate with the urban present life such as jails, military barracks, factories, and annoying industries inside the cities are reformed and in a word, the irregular growth of cities and degradation of agricultural lands and grasslands are prevented.

In inner development of city, the most attention is paid to the more effective use of lands which have been covered by the urban development. The large part of future growth of the population and the need for house in the area or city can be fulfilled through filling the extant context of the city, moderate increment of density, renovation and reconstruction of abandoned and decay areas, and reclamation and land use change of the extant old buildings. In other words, innermost development is using the whole capabilities and potential and existing capacities available in the city in order to achieve a sustainable and participatory city and promotes the whole social, physical, political, economic, and environmental structures to achieve a qualitative, quantitative, and sustainable balance.

Yasuj city, because of its position across Zagros Mountains and the soaring mountain of Dena, is among the foothill cities, with abundant natural and cultural attractions, which have been paid attention to in recent years and its growth and development are increased day by day and this issue is a disturbing factor for environment. Yasuj city continues its expansion in a sprawl way and makes the agricultural pristine lands and its surrounding gardens go under its concrete foundations. It has also taken the form of a giant who plays the role of Tehran in the 1950s in harvesting surrounding lands. The unrestrained growth of this city caused abundant concerns which if it continues in this way, we will witness a very bad situation in this ecotourism and tourism center of country in future years

\section{The Research Findings}

The first significant stage in examining every city is that a number of indices indicating the present situation of the city from the perspective of innermost development should be 


\section{Macrothink}

provided. Since the actions and organizing spaces within the existing cities will occur, but the effect of which is less visible, in order to make the innermost development of the city more tangible, first, it is necessary to plan indices with the measurement of which can assess the innermost development rate of every city with regard to the relevant standards. In the continuation of this study it will be attempted to estimate and investigate the most significant indices related to the innermost development of Yasuj city (Urban Construction and Organization, 2006).

\subsection{The Exploitation Index of Urban Land}

The exploitation of urban land means that with regard to the being expensive, scarce and nonrenewable as well as lack of the possibility of urban land imports, these lands are used by few people. The origin of Yasuj was on the agricultural lands and it is continuing its development on this desirable land day by day, and has caused missing the agricultural boom in the area. As seen in Figure 2, the sprawl development of the city is progressing towards agricultural lands. Thus, the exploitation index of urban land was not applied in the endogenous development for Yasuj city and this has caused concerns in not far in the future.

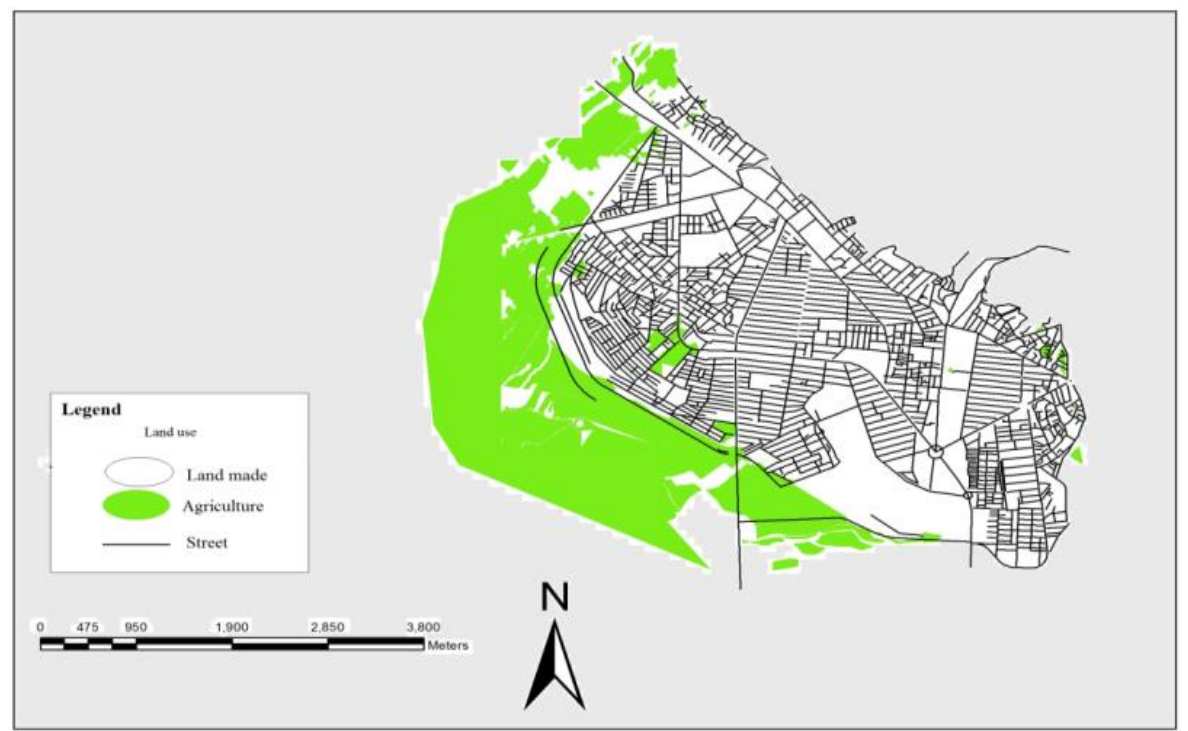

Figure 2. The exploitation of urban land (authors, 2013)

5.2 The Degradation Process Index of the Agricultural and Non-agricultural Gardens and Lands of Suburb

If the level related to this index is declining in proportion to the previous years, regarding the increasing process of the urban population, it can be an indication of the inner development of the city. But unfortunately, this index has exactly been opposed to the endogenous development for Yasuj city, and as seen in Figure 3, its growth has been in a sprawl way and has led agricultural lands and gardens to be occupied by other urban land-uses in three directions of north, northeast, and west. 


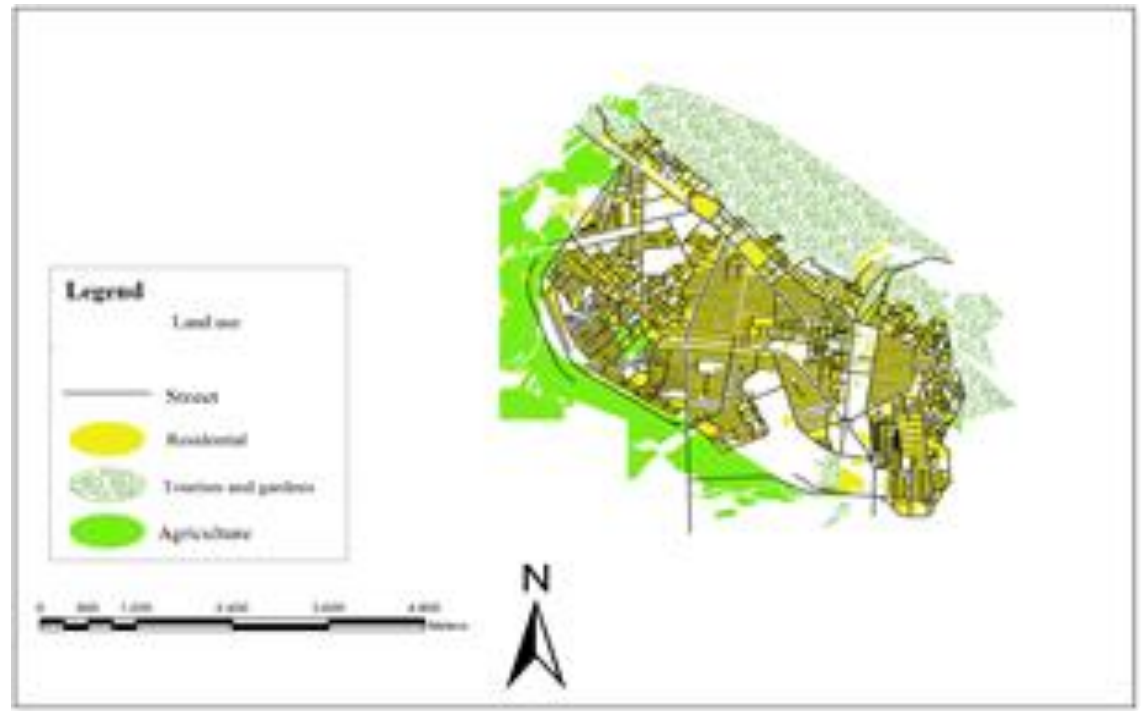

Figure 3. The degradation process the agricultural gardens and lands of Yasuj suburb (Authors, 2013)

\subsection{Social-economic Indices}

Whatever the participation rate and social awareness of the residents and owners is higher or the economic capability of the residents and citizens is higher and their comfort rate in city, neighbourhood, and residential units is higher, these can be an indication of the innermost development of the city. Unfortunately, this index is not true about Yasuj city and the local residents and owners rather than investing in the central part of the city, they lead the city growth toward their lands and cause the city grew in a sprawl form, in a way that a street in 1963 reached 18 kilometres in 2011. See Figure 4.

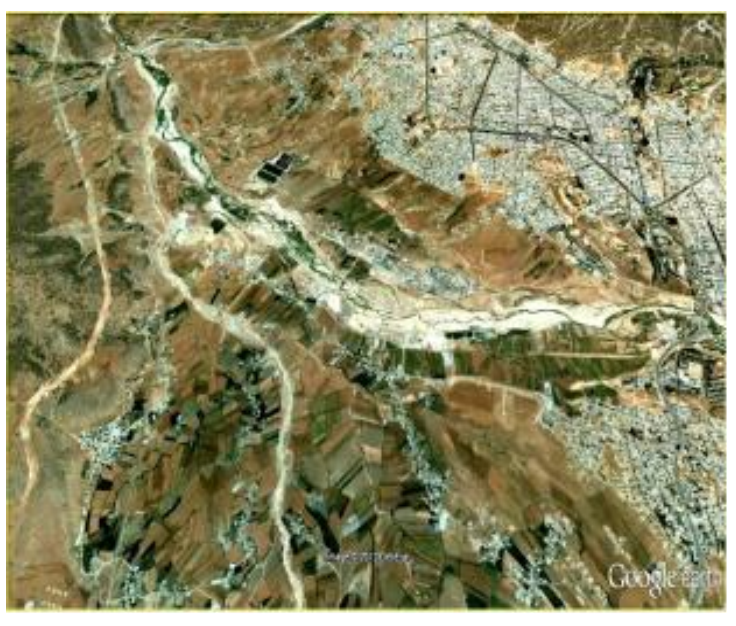

Figure 4. Building dispersion in Yasuj suburb in 2013 (authors, 2013)

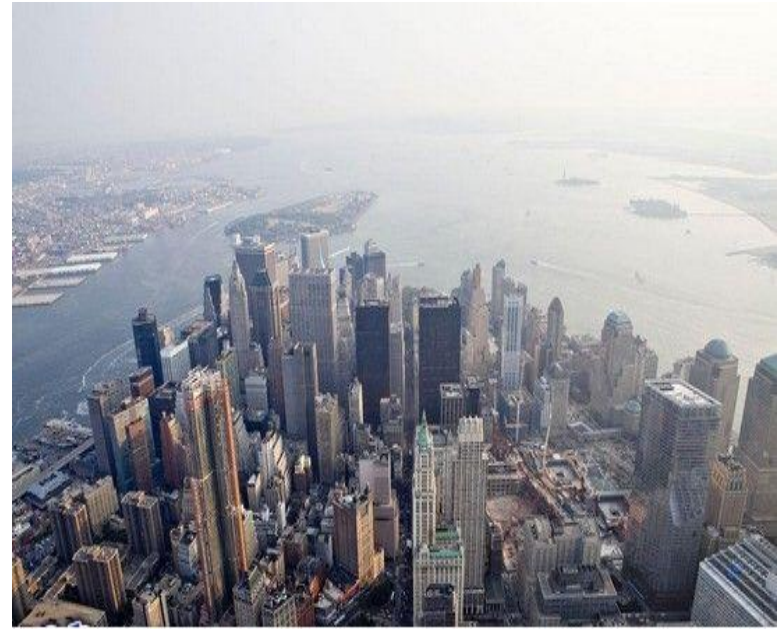

Figure 5. The New York City Center 2013 (http:// imgdl1.topnop.ir) 


\section{Conclusion and Suggestions}

Undoubtedly, the most complex urban problems and the most effectiveness of different factors exist in the central part of the city and the whole urban space and its operations are affected by any plan for city center. This reveals the importance of the issue clearly. The sustainable urban development and endogenous growth can be multi-operational (historical, economic, social, traffic, administrative, political, physical, spatial, and ecological), which has the main development operations and urban sustainability in itself.

With regard to the under examined indices in this research, a very low per cent of these indices was observed in Yasuj city, which has resulted in lack of development, as it ought to be and with regard to the potential capacity it has. It couldn't use the inner development indices for sustainable urban development. Therefore, the sprawl and unrestrained growth of the city caused destroying the pristine lands, which give beautiful scenery to the city, around the city. The agricultural lands and gardens show their appearance to other land-uses day by day, and conversely, in the central part of the city, the vertical growth has less been used. In the old parts and city center, the buildings are mostly one or two floors, the conditions of which can be because of the custom of the city residents who had little tendency to live in multi-floor and skyscraper buildings as well as the politic of local owners in development of the city towards their own lands. The most effect which the irregular growth of the Yasuj city had on preventing from sustainable urban development was destroying the environment, forests, grasslands, and gardens. Now, with the sprawl development of Yasuj city and population growth, pathways networks, traffic nodes, the polluting land uses and activities like transportation, storehouses, the vehicles repair shops, commercial and the manufactured factories imported a wide range of harmful and dangerous pollutants into the space and domain of the city. This issue is followed by many concerns for the city future and its development.

According to the conducted studies in this research and regarding the different fields of economic, social, environmental, physical, as well as preservation of agricultural lands, the presented suggestions for sustainable development planning of Yasuj city, preventing from the urban irregular growth, and degradation of surrounding agricultural lands are as follows:

- Establishing special facilities of credit and banking for investments in construction and reconstruction of the old and decay part of the city for construction of high buildings for preventing sprawl growth of the city.

- Assigning different activities to the arid lands within the city for preventing from unrestrained development of the city.

- Supporting the farmers, agricultural productions, and employing industries in order to optimal use and exploit of existing and rich resources in suburb to avoid land use changing.

- Pay attention to the optimal distribution of population and services in different parts of the city. 


\section{Macrothink Institute ${ }^{\text {tm }}$}

- Establishing the required policies for preventing the unrestrained development of the city, constructing building in suburb, and sprawl growth of the city by owners and investors.

- Preventing from indiscriminate use of resources for reducing environmental pollution.

- Making annoying industries and factories far away from the city and the agricultural lands around it.

\section{References}

AliAkbari, I. (2005). Urban development and social pathology in Iran, Geographical researches Journal, magiran.com/p 451237

Amkchi, H. (2005). The centric cities and their role in the framework of the national development, the center of studies and researches in developing cities and Iranian architecture Publishing, edition first

Bvrv, PE. (1998). Principles of geographical information system and its application in the territorial resource evaluation, HA translation of zealous and SA Masoodian, Isfahan University Publishing, edition first.

Cowen, M. P., \& Shenton, W. (1996). Doctrines of Development London an New York: Routledge. http://gigadownload.net/pliki/book_8592.zip

Dai, F. Lee, C., \& Zhang, X (2001). "GIS based geo-enviromental for urban land use planning:a case study"; Engineering geology, 61(15), 257-271.

http://dx.doi.org/10.1016/S0013-7952(01)00028- X

Ebrahimzadeh, E., \& G, Rafiee. (2010).The analysis of the sample of formational-spatial extension of Marvdasht city by using the demographic models of Shanon and Holdron and presenting the favorable sample of extension in the future, the human geographical studies, 69(12), 123-138.

http://www imgdl1.topnop.ir/uploads/201102/tpn2729/large/10eI6Ba8xa.jpg

Lynch, K. (2003). Good shape theory of city, translated by Hussein Bahrain, Tehran University Press, $\left(2^{\text {nd }}\right.$ ed $)$.

Makhdoom, M. (2000). Scientific authors and sustainable development in environment, development and environment conference, Tehran University

MohAram Nejad, N. (2008). Principles and criteria of sustainable urban development in Iran, Research Center for Architecture and Urban Studies Publishing. http://www.denaboy.pib.ir

Movahed, A. (2001). "Sustainable Urban Development", Housing and Revo-lution Monthly, $32(8), 52-64$.

Parhizkar, A. (1998). Presenting an appropriate sample to locate the civil services by research in models and civil GIS system, the Ph.d dissertation, Tarbiat Modarres university. 


\section{Macrothink}

Environmental Management and Sustainable Development

ISSN 2164-7682 2014, Vol. 3, No. 1

Qrkhlo, M., \& H. Hosseini. (2009). Indicators of Urban sustainable development, Journal of Geography and Regional Development, Spring and Summer, 42(8), 16-27.

Saifudin, F. (2000). The trend of urbanization, problem of the big cities. Geographical researchs Journal, 46(3), 12-25.

Salehi, E. (2009). The role of regulations in achieving good urban planning and sustainable development of urban case studies, Tehran, Journal of Ecology. Urban Construction and Organization, 40(2), 67-82.

Taghipoor, A. (2010). Evaluation of the spatial organization of shahrood citi with emphasis on land use patterns, educational, MA thesis, University of Tabriz.

Ziari, K. (2001). Sustainable Development and the Responsibility of Urban Planners in 21st century. Journal of Faculty of Letters and Humanities, University of Tehran.

http://jflh.ut.ac.ir/pdf_13542_c3176c07f33321c83a1121fe3ad6108a.html

\section{Copyright Disclaimer}

Copyright reserved by the author(s).

This article is an open-access article distributed under the terms and conditions of the Creative Commons Attribution license (http://creativecommons.org/licenses/by/3.0/). 